\title{
La filosofía liberal y el imperativo kantiano, una aproximación reflexiva desde el derecho al libre desarrollo de la personalidad
}

\author{
OMAR ALFONSO OCHOA \\ Politécnico Grancolombiano \\ oaochoa@superservicios.gov.co
}

Abogado con grado de Honor de la Universidad Nacional de Colombia. Especialista en Gestión Pública e Instituciones Administrativas, Universidad de los Andes; en Derecho Constitucional, Universidad Nacional de Colombia y en Derecho Privado Económico, Universidad Nacional de Colombia. Maestría en Derecho Económico Pontificia.

\section{Resumen}

El modelo de Estado adoptado por el constituyente de 1991, se sustenta en el ideario de la filosofía liberal clásica que concibe al individuo como centro del devenir histórico y en tanto tal, el Estado que encarna el interés general, tiene claros límites en su accionar frente a la esfera privada de cada asociado, ámbito en la cual este goza de una serie de derechos inalienables que no pueden ser desconocidos, vulnerados o restringidos por el Estado. En ese orden, aspectos que solo le atañen al individuo no pueden ser objeto de imposiciones heterónomas que le niegan su calidad de ser moral y lo limitan a la condicion de medio y no de fin en sí mismo, según el postulado kantiano.

\section{Palabras Claves}

Liberalismo, imperativo kantiano, Estado social de derecho, contractualismo, filosofía política.

\section{Abstract}

The model adopted by the constituent state in 1991 is based on the ideas of the classical liberal philosophy that conceives the individual as the center of the historical becoming and, with respect to it, the State that embodies the general interest. This model has clear limits on its actions towards the private sphere of each associate. An area where associates have a number of inalienable rights that cannot be unknown, violated, or restricted by the State. Therefore, issues that pertain only to the individual cannot be the object of heter onomous impositions that deny their quality of being moral and limit this individual to the condition of a means and not an end in itself, according to the Kantian postulate.

Key words

Liberalism, Kantian Imperative, Social State of Law, Contractualism, Philosophy Policy.
Fecha de recepción: 10 de septiembre de 2010 Fecha de aprobación: 30 de septiembre de 2010

\section{La tradición filosófica liberal clásica}

El liberalismo como corriente ideológica, se posiciona como reacción frente al absolutismo medieval y renacentista en los albores de las revoluciones modernas, las cuales marcaron un hito en la construcción del pensamiento contemporáneo, al enarbolar la necesidad de construir pactos sociales en los que las leyes sean la manifestación de la voluntad general en términos rousseaunianos. El ideario francés señalaba esta máxima en el artículo 2 de la declaración de Derechos del Hombre y el Ciudadano de 1789 al pregonar: "El objetivo de toda asociación política es la conservación de los derechos naturales e imprescriptibles del hombre".

Así las cosas, los derechos naturales constituyen límites al ejercicio del poder político que no pueden ser desconocidos por ese andamiaje de poder, por el contrario, la razón de ser del Estado, es la de garantizar el ámbito de la individualidad libre de intromisiones exógenas al asociado y reprimir conductas que puedan ocasionar atentados contra la libre y armónica convivencia social. De esa forma, se reafirma un postulado legatario del pensamiento kantiano, en el sentido que el derecho ajeno marca los límites infranqueables frente al ejercicio de los propios derechos.

En ese mismo orden de ideas, haciendo referencia a la tradición liberal, cobra inusitada relevancia el imperativo kantiano, "Obra de tal modo que uses la humani- 
dad, tanto en tu persona como en la de cualquier otro, siempre como un fin, y nunca sólo como un medio" ([KrV] 120). En efecto, como el individuo es un fin en sí mismo, no puede ser objeto de imposiciones ajenas en órbitas que solamente a él le competen; por ejemplo, su opción política, filosófica, religiosa, sexual, cultural, etc., las cuales se convierten en verdaderas "Cartas de batalla", que denotan el triunfo histórico del constitucionalismo moderno, fundamentado en la dignidad del ser y no es su instrumentalización que le niega el carácter de ser moral y libre para la escogencia racional de las diversas opciones sobre su desarrollo vital.

De acuerdo con los anteriores racionamientos, lo contrario al ideario liberal clásico, es la imposición de formas de pensar o de actuar por encima del libre parecer del individuo, en procura de intereses supuestamente superiores (mayoritarios, de partido, de clase, del Estado, de la iglesia, del grupo, etc.), por cuanto en últimas, ese tipo de imposiciones que no provienen del libre ejercicio racional de elección en cabeza del ser, le niegan su calidad de ente moral dotado de dignidad y lo ubican en un lugar de simple instrumento de otros intereses que se consideran superiores a su libertad, lo cual lo convierte inexorablemente en un ser alienado, cosificado y negado en cuanto a su dignidad esencial.

\section{El desarrollo histórico del ideario liberal y su pondera- ción frente a la democracia}

El sustrato común a esa primera fase del pensamiento liberal es el contractualismo como concepto que subyace a la generación de estructuras de poder en el seno de una sociedad, construcción en la cual convergen Rosseau, y Locke, y en forma decidida el enciclopedismo francés que superan además las concepciones medievales relativas al derecho divino de los reyes, propias de Bodino y Hobbes, que pregonan la impunidad de las acciones ejercidas por el soberano, por cuanto en su sentir, es el representante de la divinidad en nombre de la cual ejerce el poder, teoría superada por la ficción del contrato social que le imputa responsabilidad a quien ejerce el poder por acción u omisión y supedita su ejercicio a unas reglas previamente definidas por los destinatarios de ese ejercicio por medio de un proceso representativo.

No obstante la riqueza conceptual esbozada del ideario liberal, sufre varias modulaciones fruto de procesos históricos posteriores, que le van marcando un perfil de adaptación necesaria a las nuevas realidades sociales.

En efecto, el ideario liberal clásico mantiene su robustez en lo relativo a las libertades individuales como límite frente al ejercicio arbitrario del poder político, pero empieza a mostrar falencias en lo relativo a la materialidad de los derechos que formalmente reconoce, especialmente el de igualdad, el cual no pasa de ser un postulado desprovisto de eficacia práctica, que implica que esa igualdad no sea real y efectiva, sino que las diferencias económicas y naturales marcan la pauta de diferenciación que ni la ley ni el Estado corrigen.

Así las cosas, era necesario que se dejara de lado la teoría del "laissez faire, laissez passer" y se pasara a un modelo económico en el cual el Estado corrigiera con su accionar positivo las fallas del mercado, lo cual implicó la superación del Estado mínimo, por uno que al contrario interviniera activamente en los procesos productivos.

En ese contexto, el liberalismo también se introduce en esos nuevos debates y surgen tendencias que superan la simple apropiación individual de los derechos, para extender su margen de acción a la utilidad social del accionar del Estado. Es el caso del liberalismo que pregona Jeremías Benthan y Jhon Stuart Mill, frente al utilitarismo como lógica operadora, según la cual, lo justo es propiciar el mayor nivel de felicidad al mayor número posible de asociados, no solamente relegarnos en la perspectiva del derecho natural que implica deberes de abstención por parte del Estado, sino la exigencia por desplegar iniciativas que proporcionen bienestar a la mayoría del conglomerado, actuando dentro de la lógica del libre mercado. Ello lleva implícito un menoscabo a los intereses minoritarios, los cuales van a ser reivindicados por la teoría madisoniana, que reivindica en una democracia los derechos de las minorías frente a la tiranía de las mayorías, como un rasgo consustancial al ideario de concreción de la democracia de corte liberal.

En el siglo XX la revolución mexicana, el triunfo de los bolcheviques en la Rusia zarista y la expedición de la Constitución social de Weimar en Alemania, precipitan los cambios anunciados, situación que se ve agudizada con el advenimiento de la crisis bursátil de los años 
1930 y la instauración del "welfare state" como alternativa de ajuste al Estado de corte capitalista, el cual se consolida en la posguerra como la estructura imperante en occidente hasta la década de los setenta, cuando fruto de los desbalances fiscales, empieza a mostrar síntomas de superación por el Estado de talante neoliberal, que surge de nuevo como alternativa frente a las falencias del Estado bienestar.

La historia es cíclica y de nuevo el ideario de estirpe liberal cobra validez en la moderna teoría política como alternativa para la construcción de modelos de Estado, máxime después del colapso de la Europa del este, hecho que para algunas voces implicó el fin de la historia (Fukuyama, 1992) y el afianzamiento de la democracia de talante liberal como única alternativa viable hacia el futuro, frente a la cual, autores como Huntington (1997), proclaman que solamente el fundamentalismo del Islam, sería un factor que pondría en riesgo su hegemonía mundial.

Ubicados en la perspectiva liberal, Jhon Rowls ha planteado desde la década de los noventa, la "Teoría de la justicia”, como una forma de organización social en la cual es posible la coexistencia pacífica de diferentes tendencias políticas, ideológicas y religiosas, siempre y cuando exista un acuerdo elemental sobre el respeto a la diversidad y la tolerancia como valores sociales, los cuales constituyen el motor de una sociedad justa, conformada por hombres libres, sobre los que en el texto mencionado asevera: "Cada persona debe gozar de un ámbito de libertades tan amplío como sea posible, compatible con el ámbito igual de libertades de cada uno de los demás" (Rowls, 1999).

\section{El Estado social de derecho y el ideario constitucional colombiano}

Hermann Heller (Monereo Pérez, 2009: 10) teórico de la ciencia política alemana, fue el primero en acuñar la categoría "Estado social de derecho" en la década del veinte, la cual se asumiría como propia de los Estados de la posguerra en Europa, por ejemplo, las constituciones italiana y francesa de 1948, la ley fundamental de Boon de 1949, entre otras. Especial importancia reviste la Constitución española de 1978, pacto político que marca la superación de la tradición, que desde finales de la década de los treinta había caracterizado a España como una sociedad corporativa, para dar paso a una democracia moderna que hace suyo el ideario propio del Estado social de derecho.

Este texto constitucional es, sin duda, el referente que adoptó el constituyente del año 1991 en el país, al transpolar varias de las instituciones plasmadas en el mismo al caso colombiano. El Estado social de derecho es una categoría que va más allá a la de simple "Estado de derecho", por cuanto en aquella, el Estado no solamente se limita a reconocer formalmente los derechos, sino que tiene la obligación de desarrollar mecanismos para que los mismos se hagan materialmente efectivos.

Es así como nuestra Constitución, consigna expresamente que Colombia es un Estado social de derecho, organizado en forma de república unitaria, con descentralización y autonomía de sus entidades territoriales, en el cual se reconocen como fines esenciales promover la prosperidad general, garantizar los derechos y deberes consagrados en la Constitución, facilitar la participación de todos en las decisiones que los afecten, entre otros. Desde el mismo preámbulo se anuncia el carácter laico y secular del nuevo modelo de Estado, al señalarse expresamente que el poder soberano reside en el pueblo, superando el confesionalismo propio de la Constitución de 1886, que partía del supuesto de que Dios era la fuente suprema de todo poder.

En su parte dogmática, la Constitución, al igual que el ideario liberal clásico, reconoce una serie de derechos denominados civiles y políticos, entre los cuales destacamos la vida, la integridad, la igualdad, la intimidad, el libre desarrollo de la personalidad, la proscripción de la esclavitud y la servidumbre, y la libertad de conciencia, de cultos, de asociación y de enseñanza, entre otros. Esa serie de derechos son propios de la tradición liberal que datan de las revoluciones: francesa, inglesa y norteamericana, y recalcan el papel del Estado como garante de los mismos, reconociendo una órbita del individuo que le está vedada al accionar del Estado, so pena de violar el pacto político.

En este punto se debe resaltar que las constituciones son dispositivos de control al ejercicio del poder político en términos de Ferdinand Lasalle, en su ilustre y connotado ensayo ¿Qué es una Constitución? (Wenceslao Roces, 1984). De igual modo, las constituciones son "Cartas de batalla" que la humanidad ha ganado, fruto de tortuosos procesos históricos para reivindicar sus 
derechos frente a la arbitrariedad y la tiranía; en esa medida, los derechos que reconocen no son simples buenas intenciones del gobernante de turno, ni graciosas concesiones de quien detenta el poder, sino límites infranqueables para quien lo ejerce.

Desde esa perspectiva, al analizar el contenido del texto constitucional de 1991, concluimos inexorablemente que el mismo está fuertemente imbuido, en esta primera parte dogmática, del ideario propio del liberalismo libertario y que hace suyos los postulados kantianos en torno al imperativo categórico que prevalece como postulado, cuando señala que el ser humano es un fin en sí mismo y no un simple instrumento para la realización de otros fines que lo trasciendan.

\section{La crisis del modelo constitucional liberal en el con- texto del Estado comunitario}

La filosofía política que ha inspirado el ideario del Estado social de derecho, se encuentra en la actualidad en entredicho en medio de un contexto donde hemos asistido a una serie de contrarreformas desde la década anterior, que desvirtúan la razón de ser del texto constitucional original del año 1991 y con ello ponen en duda la vigencia de las ideas de estirpe liberal, que sirvieron como asidero para la construcción de las modernas instituciones políticas.

Para el efecto, es pertinente remitirnos al debate en boga en torno a la penalización de la dosis personal de estupefacientes que surtió tránsito legislativo como acto reformatorio de la Constitución, en el seno del Congreso de la República por iniciativa gubernamental, la cual fue aprobada en la legislatura que terminó en 2009. Sobre el particular, es preciso señalar que desde 1994 en virtud de la sentencia C-221 de 1994 proferida por la Corte Constitucional, se despenalizó el consumo de la dosis personal de estupefacientes, entre otras razones, por considerar que la criminalización de esa conducta, implicaba el desconocimiento de un ámbito que le es autónomo al individuo. Esto se produjo bajo el entendido que esa restricción implicaba una injerencia indebida del Estado en el ejercicio de una actividad que solamente al individuo le compete, dentro del ámbito de su libertad personal y que la misma solamente puede ser restringida en la medida en que se afecten derechos de terceros, razonamiento consecuente, con el ideario de la filosofía de estirpe liberal que hemos indicado, es el referente de nuestro Estado social de derecho, como formula jurídico-política prohijada por el ordenamiento constitucional vigente.

Ponderemos un argumento a favor, para mediante un ejercicio antitético, arribar a alguna conclusión frente al ideario que ha permeado nuestra Carta de derechos.

Se indica por parte de los defensores de penalizar la dosis personal, que el Estado no puede ser indiferente frente a quien se autoinflinge daño en su salud y, por tanto, es su deber actuar para someterlo, así sea por la fuerza, a un tratamiento médico para que supere la adicción que se estima nociva para la salud.

En torno al deber del Estado de intervenir frente a un individuo aun en contra de su voluntad, para salvaguardar la salud del mismo, a pesar de su decisión voluntaria y soberana de consumir estupefacientes, la respuesta no es otra desde el liberalismo, sino la de la denuncia de la arbitrariedad que ello entraña, por cuanto con ese proceder se le despoja del carácter de ser moral al individuo, ubicándolo simplemente en el plano de la cosificación y alienación que niegan en últimas su dignidad esencial.

En efecto, nada más proclive a la tiranía que considerar los resultados de un modelo de Estado en el cual el mismo se abroga facultades paternalistas, para negarle el legítimo ejercicio de un derecho a un individuo, en aras de supuestamente protegerlo, postulado contrario a la mayoría de edad a que se refería Kant en su célebre texto: la respuesta a la pregunta: ¿Qué es la ilustración? en su obra Filosofía de la Historia, en donde se refiere a ese estado, como aquel en el cual el hombre se atreve a pensar por sí mismo y a no esperar que otros lo hagan por él.

Respecto a ese particular, la raza humana ha evidenciado especial temor al ejercicio de su libertad, como lo advertía magistralmente Erich Fromm (1991) en su texto el Miedo a la libertad, en lugar de asumir las riendas de su propio destino, el hombre se refugia en el partido, la clase social, el grupo religioso, etc. y de esa forma elude su responsabilidad histórica como artífice de sí mismo, como lo advertía atinadamente Niestzche (2005). 
Ese tipo de postulados de carácter asistencialista y de corte paternalista, son propios de Estados fascistas, en los cuales el individuo es trascendido por la corporación y los altos intereses que encarna el partido único. El mismo Kant advertía los peligros de esta forma de ejercer el poder que concibe al individuo como un ser incapaz y limitado al que hay que guiar:

Un gobiemo basado en el principio de benevolencia hacia el pueblo. Como el gobierno de un padre sobre los hijos, es decir, un gobierno paternalista (imperium paternale), en el que los súbdititos, como hijos menores de edlad que no pueden distinguir lo que es útil o dañoso, son constreñidos a comportarse tan solo pasivamente, para esperar que el jefe de Estado juzgue la manera en que ellos deben ser felices, y a esperar que por su bondad él lo quiera, es el peor despotismo que pueda imaginarse (Bobbio, 1985, 24).

Como se aprecia, el argumento enunciado, no logra derrotar el principio "pro libertad", que se erige en un referente constitucional de forzosa observancia y que es propio de un Estado que ha acogido explícitamente el ideario legatario del liberalismo, como sustento filosófico para el ejercicio de los derechos y libertades públicas.

\section{Discusión}

La Constitución Política de 1991, en materia del reconocimiento de derechos de primera generación ha acogido el ideario consolidado a raíz del triunfo histórico de las ideas del liberalismo clásico en la materia, las cuales privilegian al individuo por sobre las estructuras del Estado. En efecto, el Estado solamente tiene sentido, si su accionar se encamina exclusivamente al servicio del ciudadano y no al contrario.

En ese orden de ideas, el individuo es titular es una esfera que solamente a él le compete y que está conformada por un cúmulo de derechos que son anteriores al surgimiento del Estado, como la vida, la integridad, la libertad, y en esa medida, se trata de claros límites al ejercicio del poder político que no pueden ser desconocidos impunemente.

La función del Estado frente a los derechos inalienables que hemos reseñado, no es otra que su protección, evitando indebidas injerencias extrañas a la voluntad razonada del ser, así como garantizar las condiciones necesarias para el cabal ejercicio de los derechos y li- bertades en un marco de concordia y armonía social.

Por otro lado, ante el abuso en el ejercicio de los derechos que implique el desconocimiento o la vulneración de los derechos de otros, es deber ineludible del Estado actuar positivamente para restablecer el orden quebrantado, en procura de salvaguardar los derechos vulnerados o amenazados de un individuo.

Iniciativas como la penalización de la dosis personal de estupefacientes, lejos de propender por brindar el mayor nivel de felicidad a los asociados, lo que originan es el desconocimiento de ese íntimo ámbito del ser que le es inexpugnable a la acción del Estado, dentro del contexto de la filosofía de raigambre liberal que inspira nuestra institucionalidad, so pena de caer en un Estado paternalista, que niega las libertades en aras de supuestos intereses superiores al desconocer el carácter de fin en sí mismo del ser humano y nos ponen a las puertas de la tiranía en nombre del bienestar colectivo que encarna el Estado, aserto que sustentó en su momento el ascenso tanto de Mussolini como de Hittler al poder en sus respectivas sociedades, con las consabidas y fatales consecuencias postreras de esa situación para la humanidad.

La Corte Constitucional en la sentencia citada, advierte en torno a las consecuencias de acoger posiciones propias de Estados paternalistas que se erigen en guardianes de la moral de sus asociados al señalar:

Bajo el tratamiento de ciertas conductas que se juzgan desviadas, como enfermedades, se esconde el más feroz poder represivo, tanto más censurable, cuanto más se presenta como una actitud paternal (casi amorosa) frente al disidente. La reclusión en establecimientos psiquilátricos - similares, ha sido, desde hace mucho, un vitando mecanismo usado por los regímenes totalitarios para "curar a los heterodoxos" y las sociedades contemporáneas se han empeñado en tratar a los drogadictos como heterodoxos, pero heterodoxos enfermos a quienes hay que hacerles ver el mundo como lo ven los gobernantes.

Sobre el punto anota Szasz, con su habitual agudeza:

el hecho de drogarse no es una enfermedad involuntaria, es una manera totalmente deliberada de afrontar la dificulltad de vivir, la enfermedad de vivir. Pero como no sabemos curar la enfermedad de vivir, preferimos "tratar" al dirogadicto (Gaviria Diaz, 2001, 13). 
Bajo esa óptica, el Estado debe robustecer las políticas educativas en materia de prevención e información, como una medida profiláctica para atacar la problemática que el consumo de sustancias adictivas genera, así como propiciar espacios para quien voluntariamente quiera someterse a un tratamiento de rehabilitación y superación de la adicción, recordando que tanto la Organización Mundial de la Salud como la Asociación Americana de Siquiatría, consideran a la drogadicción como una enfermedad crónica, así las cosas, no es por vía de la criminalización de la conducta que se alcanzará la solución a esa compleja situación.

Ya lo advertía Maquiavelo desde los albores del Medioevo, el príncipe tiene que parecer el modelo moralista a seguir para lograr la plena adscripción de sus súbditos, incluso en su vida personal, los cuales no se conciben como ciudadanos libres y dignos, sino como simples piezas manipulables en el engranaje colectivo.

Considerar a la persona en calidad de autónoma como lo hace la Constitución, tiene sus consecuencias directas, tal vez la más relevante consiste en que los asuntos que solamente a ella atañen, solo por ella deben ser decididos, de lo contrario estaremos transitando la peligrosa senda que nos conduce a la tiranía, considerada desde la antigua Grecia como el mal más peligroso de todos los sistemas para el adecuado funcionamiento del andamiaje social.

Desde la filosofía liberal, es preciso pregonar, como una consigna con validez perenne y plenamente aplicable a la presente temática que: "Una vez que se ha optado por la libertad, no se le puede temer...".

\section{Bibliografía}

1. Bobbio, Norberto. (1985) Liberalismo y democracia. México: Fondo de Cultura Económica.

2. Chevallier, Jean Jacques. (1997) Las grandes obras políticas. Bogotá: Editorial Témis.

3. Corte Constitucional. (1994). Sala Plena. Sentencia C-221 de 1994 MP Carlos Gaviria Díaz.

4. Fromm Erich. (1991). El miedo a la libertad. Buenos Aires: Editorial Paidós.
5. Fukuyama, Francis. (1992). El fin de la historia y el último hombre. Madrid: Editorial Planeta.

6. Gaviria Díaz, Carlos. (2001) Herejías constitucionales. Bogotá: Fondo de Cultura Económica.

7. Huntington, S. P. (1997). El choque de civilizaciones y la reconfiguración del orden mundial. Barcelona: Editorial Paidós.

8. Lasalle, Ferdinand. (1984). "QQué una Constitución?" (trad. Wenceslao Roces) Madrid: Ariel.

9. Kant, Immanuel. [KrV] (1998). Crítica de la razón pura (trad. P. Ribas). Madrid: Alfaguara.

10. Kant, Immanuel. (1995). Filosofía de la Historia. Buenos Aires: Editorial Nova.

11. Monereo Pérez. (2009). La defensa del estado social de derecho. La teoría política de Hermann Heller. Madrid: Intervención Cultural.

12. Nietzsche, Friedrich. (2005). Así habló Zaratustra. Madrid: Alianza Editorial.

13. Rawls, Jhon. (1999). Justicia como equidad. Madrid: Editorial Tecnos.

14. Rosseau Jean Jacques. (2009). El contrato social. México: Edimat libros.

15. Sabine, George. (1999). Historia de la Teoría Política. México: Fondo de Cultura Económica. 